\title{
Synthesis and Characterization of Cobalt(III) Octahedral Complexes with Flexible Salpn Schiff Base in Solution. Structural Dependence of the Complexes on the Nature of Schiff Base and Axial Ligands
}

\author{
Rasoul Vafazadeh $^{\star}$ and Marỵam Kashfi \\ Department of Chemistry, Yazd Lniversit, vazd. Iran. 'E-mail. mafazadehôuazduniacir \\ Received Mav 31, 2007
}

Key Words : Schiff base, ${ }^{1} \mathrm{H}$ NMR. Salpn, Cobalt complexes. Flexibility

For a long time tetradentate Schiff base complexes of transition metal ions have attracted many researchers interest in the field of coordination chemistry. ${ }^{1-5} \mathrm{Co}$ (III) complexes of Schiff base are an important class of coordination compound not only because of them being interesting $\mathrm{B}_{12}$ models and oxygen carriers but also due to their interesting magnetic properties spectroscopic characteristics and the interaction of metal-to-ligand bonds. ${ }^{4-9}$

Many studies initially focus on simple Schiff base ligand such as salophen. salen and acacen $(n=2)$ Scheme $1^{1.4 .5 .11 .11}$ but interest quickly shift to more intricate species which have extra functional groups. side chains and more methylene groups in the amine backbone..$^{2-15}$ A number of strucnural studies on the effect of the number of $\mathrm{CH}_{2}$ groups between the two imine moieties in $\mathrm{VO}^{--} \cdot \mathrm{Co}^{--} \cdot \mathrm{Ni}^{-} \cdot \mathrm{Cu}^{2+}$ and $\mathrm{Zn}^{2+}$ complexes ${ }^{16-2=}$ of tetradentate Schiff bases derived from salicylaldehyde and a variety of diamines ( $1: 2$ ratio) have been carried out previously. They have been shown that an increase in the methylene chain length allows adequate flexibility for the complexes to change their structure from a planar towards a distorted or pseudo-tetrahedral motif. In addition. the longer chains cause the ligand field strength to decrease. ${ }^{15.21}$

Among the cobalt Schiff base complexes. the best known is Co(salen). which has a square planar geometry about the cobalt(II) ion. ${ }^{18.19}$ Magnetic susceptibility measurements indicate that a low spin electronic configuration with the single unpaired electron residing in a molecular orbital of primarily $\mathrm{d}_{2}$ ' character. which is consistent with esr measurements. 8.19.23:- Although Co(III) octahedral complexes with salophen. salen and acacen $(n=2)$ have been known. ${ }^{4.5 .10 .11}$ octahedral complexes with higher number of $\mathrm{CH}_{2}$ groups in Schiff base $(n \geq 3)$ such as salpn or acacpn have not been reported. The Co' (salpn) complex's reactivity toward bases was markedly different from that of $\mathrm{Co}^{\mathrm{ll}}$ (salen). The
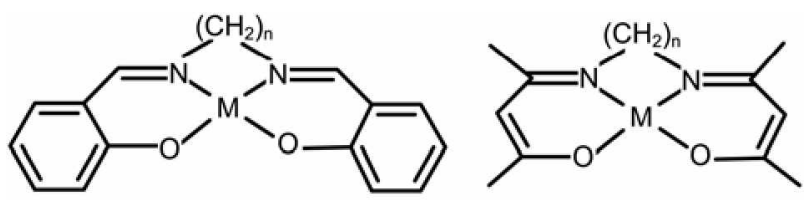

$\mathrm{n}=2$, salen $\mathrm{n}=3$, salpn $\mathrm{n}=2$, acacen $\mathrm{n}=3$, acacpn

Scheme 1
$\mathrm{Co}^{\mathrm{II}}$ (salen) complex is extremely oxygen sensitive and in the presence of an additional donor group fonms six coordinated octahedral cobalt(III) complexes. whereas the $\mathrm{Co}^{\mathrm{II}}$ (salpn) complex shows a low tendency to increase its coordination number in the presence of additional donors such as $\sigma$-donor bases. In order to investigate the effect of the number of methylene groups on the coordination behaviors. we have synthesized the cobalt(III) octahedral complexes with the $\mathrm{H}_{2}$ salpn Schiff base $(n=3)$.

\section{Experimental}

Physical measurements. UV-Vis spectra in solution were recorded in acetone solvent on a Jasco 7800 spectrophotometer. IR spectra were recorded as $\mathrm{KBr}$ pellets in an Equinox 55 Bruker spectrophotometer. All NMR measurements were made in $\mathrm{CDCl}_{3}$ or DMSO- $d_{6}$ on a Bruker Advancer 500 $(500 \mathrm{MHz})$ NMR spectrometer. Proton chemical shifts are reported in parts per million (ppm) relative to an internal TMS standard. Elemental analys șes were performed by using a Heraeus C.HN-O-RAPID elemental analyzer.

Syntheses. $\mathrm{H}_{2}$ salpn Schiff base was prepared as reported in the literature ${ }^{19}\left[\mathrm{Co}^{\mathrm{II}}\right.$ (salpn)] complex was synthesized according to the reported method. ${ }^{19}$

trans-[Co ${ }^{\mathrm{II}}$ (salpn)(amine) $\left.\left(\mathrm{N}_{3}\right)\right]$ complexes. To a stirred suspension of 1 minol $(0.34 \mathrm{~g})$ of the $\mathrm{Co}^{\mathrm{II}}(\mathrm{salpn})$ complex in $70 \mathrm{~mL}$ dry methanol. $2 \mathrm{mmol}$ of the appropriate anine was added. Air was bubbled slowly through the reaction mixture for $3.5 \mathrm{~h}$. To the resulting solution $1 \mathrm{mmol}(0.065 \mathrm{~g})$ of solid $\mathrm{KN}_{3}$ was added and air was bubbled in for a further $0.5 \mathrm{~h}$. The resulting solution was left overnight. giving a green oil form. The green oil obtained was resuspended in ether (15 $\mathrm{ml}$ ) and stirred at room temperature until a precipitate fomed. The green solid product was recrystallized from suitable solvents according to the following procedures:

- The $\left[\mathrm{Co}^{\mathrm{II}}(\mathrm{salpn})(\mathrm{py})\left(\mathrm{N}_{3}\right)\right]$ complex (1) was recry stallized from dichloromethane:cyclohexane $(2: 1 \mathrm{v} / \mathrm{v})$ as a green powder. The powder was filtered off, washed with cyclohexane and dried under vacuum. Yield $40 \%(0.4 \mathrm{mmol}$. 0.184 g). Anal. Calc for $\mathrm{C}_{2} \mathrm{H}_{21} \mathrm{~N}_{6} \mathrm{O}_{2} \mathrm{Co}: \mathrm{C} .57 .38: \mathrm{H} .4 .60$ : N. 18.26. Found: C. 57.32: H. 4.81: N. 17.96\%. FT-IR ( $\mathrm{KBr}$ $\left.\mathrm{cm}^{-1}\right): 2027 \mathrm{~s}\left(v \mathrm{~N}_{3}\right): 1623 \mathrm{~s}(v \mathrm{C}=\mathrm{N}): 1538 \mathrm{~m}(v \mathrm{C}=\mathrm{C})$. UVVis (acetone) dd. $611 \mathrm{~nm}\left(\varepsilon=199 \mathrm{M}^{-1} \mathrm{~cm}^{-1}\right)$.

- The $\left[\mathrm{Co}^{\mathrm{III}}(\mathrm{salpn})(3-\mathrm{Mepy})\left(\mathrm{N}_{2}\right)\right]$ complex (2) was 
recrystallized from dichloromethane:ethanol:cyclohexane $(2: 2: 1 \mathrm{v} / \mathrm{v} / \mathrm{v})$ as a green powder. The powder was filtered off. washed with cyclohexane, and dried under vacuum. Yield $35 \%\left(0.35\right.$ mumol. 0.166 g). Anal. Calc. for $\mathrm{C}_{23} \mathrm{H}_{33} \mathrm{~N}_{6} \mathrm{O}_{2} \mathrm{Co}$ : C. 58.21: H. 4.89: N. 17.72. Found: C. 57.94: H, 5.05: N. $17.42 \%$. FT-IR $\left(\mathrm{KBr} \mathrm{cm}^{-1}\right): 2027 \mathrm{~s}\left(v \mathrm{~N}_{3}\right): 1622 \mathrm{~s}(v \mathrm{C}=\mathrm{N})$ : $1538 \mathrm{~m}(v \mathrm{C}=\mathrm{C})$. UV-Vis (acetone) dd, $612 \mathrm{~nm}\left(\varepsilon=192 \mathrm{M}^{-1}\right.$ $\left.\mathrm{cm}^{-1}\right)$.

- The $\left[\mathrm{Co}^{\mathrm{II}}(\mathrm{salpn})(4-\mathrm{Mepy})\left(\mathrm{N}_{3}\right)\right]$ complex (3) was purified by a similar method to the complex (1). Yield $44 \%$ $\left(0.44\right.$ mumol, 0.209 g). Anal. Calc. for $\mathrm{C}_{23} \mathrm{H}_{33} \mathrm{~N}_{6} \mathrm{O}_{2} \mathrm{Co}: \mathrm{C}$. $58.21 ;$ H. 4.89; N. 17.72. Found: C. 57.87; H. 5.11; N. $17.54 \%$. FT-IR $\left(\mathrm{KBr} \mathrm{cm}^{-1}\right): 2028 \mathrm{~s}\left(v \mathrm{~N}_{3}\right): 1624 \mathrm{~s}(v \mathrm{C}=\mathrm{N})$ : $1538 \mathrm{~m}(v \mathrm{C}=\mathrm{C}) . \mathrm{UV} \cdot \mathrm{V}_{1 \mathrm{~s}}$ (acetone) dd. $61 \mathrm{lmm}\left(\varepsilon=156 \mathrm{M}^{-1}\right.$ $\mathrm{cm}^{-1}$ ).

- The $\left[\mathrm{Co}^{\text {III }}(\right.$ salpn) $\left.)(3-\mathrm{CNpy})\left(\mathrm{N}_{3}\right)\right]$ complex (4) was recrystallized from dichloromethane:cyclohexane $(1: 1 \mathrm{v} / \mathrm{v})$ as a green powder. The powder was filtered off. washed with cyclohexane and dried under vacuum. Yield 25\% $(0.25$ mmol. $0.125 \mathrm{~g}$ ). Anal. Calc. for $\mathrm{C}_{2} \mathrm{H}_{22} \mathrm{~N}_{7} \mathrm{O}_{2} \mathrm{Co}: \mathrm{C}, 57.72: \mathrm{H}$. 4.44: N. 19.63, Found: C, 57.52; H. 4.67; N, 19.31\%. FT-IR $\left(\mathrm{KBr} \mathrm{cm}{ }^{-1}\right): 2028 \mathrm{~s}\left(v \mathrm{~N}_{3}\right) ; 1623 \mathrm{~s}(v \mathrm{C}=\mathrm{N}) ; 1539 \mathrm{~m}(v \mathrm{C}=\mathrm{C})$. UV-Vis (acetone) dd. $610 \mathrm{~nm}\left(\varepsilon=162 \mathrm{M}^{-1} \mathrm{~cm}^{-1}\right)$.

trants-[Co ${ }^{\mathrm{II}}$ (salpn)(amine) $\left.)_{2}\right] \mathrm{ClO}_{4}$ complexes. To a stirred suspension of $\mathrm{I}$ mmol $(0.34 \mathrm{~g})$ of the $\mathrm{Co}^{\mathrm{II}}($ salpn) conplex in $70 \mathrm{~mL}$ dry methanol. $3 \mathrm{mmol}$ of the appropriate amine was added. Air was bubbled slowly through the reaction mixture for $3 \mathrm{~h}$. To the resulting solution $0.15 \mathrm{~g}$ of solid $\mathrm{NaClO}_{4}$ was added and air was bubbled in for 1 more hour. The resulting clear brown solution was left overnight to give a brown precipitate. The following complexes were recrystallized as shown below, filtered off, wash with ethanol and dried in vacuum at room temperature.

$-\left[\mathrm{Co}^{\mathrm{II}} \text { (salpn)(py) }\right)_{2} \mathrm{ClO}_{4}$ complexes. (5): was recrystallized from dichloromethane-ethanol $(2: 1 \mathrm{v} / \mathrm{v})$ as a green powder. Yield $34 \%(0.34 \mathrm{munol}, 0.203 \mathrm{~g})$. Anal. Calc. for $\mathrm{C}_{27} \mathrm{H}_{26} \mathrm{~N}_{4} \mathrm{O}_{6} \mathrm{ClCo}: \mathrm{C}$, 54.33: H. 4.39: N. 9.39. Found: $\mathrm{C}$. 54.21: H. 4.35: N. 9.52\%. FT-IR $\left(\mathrm{KBr} \mathrm{cm}{ }^{-1}\right): 1624 \mathrm{~s}(v$ $\mathrm{C}=\mathrm{N}) ; 1540 \mathrm{~m}(v \mathrm{C}=\mathrm{C}) ; 1095 \mathrm{vs}\left(v \mathrm{ClO}_{4}^{-}\right)$. UV-Vis (acetone) dd. $565 \mathrm{~nm}\left(\varepsilon=235 \mathrm{M}^{-1} \mathrm{~cm}^{-1}\right)$.

- $\left[\mathrm{Co}^{\mathrm{II}}(\mathrm{salpn})\left(+-\mathrm{Mepy}_{2}\right] \mathrm{ClO}_{4}\right.$ complexes. (6): was recrystallized from dichloromethane-ethanol $(3: 1 \mathrm{v} / \mathrm{v})$ as a green powder. Yield $39 \%(0.39 \mathrm{mmol} .0 .244 \mathrm{~g})$. Anal. Calc. for $\mathrm{C}_{2} \mathrm{H}_{3(1} \mathrm{N}_{4} \mathrm{O}_{6} \mathrm{ClCo}$. C. $55.73 ;$ H. 4.84: N. 8.96, Found: $\mathrm{C}$. $55.94 ; \mathrm{H}, 4.91 ; \mathrm{N}, 8.86 \%$. FT-IR $\left(\mathrm{KBr} \mathrm{cm}{ }^{-1}\right): 1623 \mathrm{~s}(v$ $\mathrm{C}=\mathrm{N}) ; 1540 \mathrm{~m}(v \mathrm{C}=\mathrm{C}) ; 1095 \mathrm{vs}\left(v \mathrm{ClO}_{4}^{-}\right)$. UV-Vis (acetone) dd. $567 \mathrm{~nm}\left(\varepsilon=219 \mathrm{M}^{-1} \mathrm{~cm}^{-1}\right)$.

\section{Results and Discussion}

Synthesis of octahedral Co(III) complexes with salen or other Schiff bases having $n=2$ is easily accomplished by addition of appropriate axial ligands to $\mathrm{Co}^{\mathrm{II}}(\mathrm{salen})$ and oxidation of $\mathrm{Co}$ (II) to $\mathrm{Co}$ (III). ${ }^{3}, 0 \mathrm{C}$ However, the $\mathrm{Co}$ (salpn) complex shows only a low tendency to increase its coordination number. The observed difference in behavior is due to the structural differences between $\mathrm{Co}^{\mathrm{II}}$ (salpn) and $\mathrm{Co}^{\mathrm{II}}($ salen) .
The Co (salen) complex has a low spin square planar structure with a signle unpaired electron and a magnetic moment of about $2.5 \mathrm{BM}^{17}$ and it is extremely oxygen sensitive. In contrast the observed value of $\mu(4.56 \mathrm{BM})$ for the $\mathrm{CO}^{\text {II }}($ salpn) complex eliminates a low spin square planar or a high spin octahedral formation. ${ }^{19}$ The magnetic moment is instead in agreement with tetrahedral or pseudo tetrahedral structure.

Increasing the number of the methylene units in diamine chain of the Schiff base ligand (Schem 1) allows the Co(II) complexes to change from a square planar $(n=2)$ to a tetrahedral motif. ${ }^{20,1,1,27}$ While the $C o$ (salen) complex has no geometrical distortion with respect to the primary ligand. Co(salpn) has a distorted structure. This is in contrast to the $\mathrm{Ni}(\mathrm{II})$ series. which maintains a square planar geometry with an increase in the number of the methylene groups, or adopts an octahedral geometry if additional donor (MeOH. DMF, DMSO) are present. ${ }^{19,2 i j}$

The distortion about the cobalt center due to the extra methylene groups which causes an apparent weakening of the ligand field strength. In other words, the increasing chain length in salpn allows more flexibility to form a tetrahedral coordination geometry about the cobalt (The cobalt(II) shows a more pronounced tendency for the formation of tetrahedral complexes than either $\mathrm{Ni}(\mathrm{II})$ or $\mathrm{Cu}(\mathrm{II})$ does). ${ }^{.8}$ Therefore, $\mathrm{CO}^{\text {II }}$ (salpn) complex shows a low tendency to increase its coordination number by forming octahedral complexes in the presence of addition donors. ${ }^{8,2}$ However, relatively strong $\pi$-acceptor ligands (for example pyridine and its derivatives. or anions such as $\mathrm{N}_{3}, \mathrm{CN}$ ) increase effectively the ligand field strength. The increase in ligand field strength should facilitate the oxidation of the $\mathrm{Co}$ (II) and the formation of $\mathrm{Co}$ (III) with a trans octahedral structure.

Spectral characterization. The $\mathrm{O}-\mathrm{H}$ streching frequency of the free ligand is displaced to the $2500-2600 \mathrm{~cm}^{-1}$ region due to the internal hydrogen bond $\mathrm{OH}-\mathrm{N}=\mathrm{C} .{ }^{30,31}$ The ligand is relatively planar, with a geometrical arrangement favoring the formation of the hydrogen bond ${ }^{3 i}$ The $\mathrm{C}-\mathrm{O}$ stretching frequency is found as a medium band near $1280 \mathrm{~cm}^{-1}$ in the free ligand and $1318 \mathrm{~cm}^{-1}$ in these complexes. The IR spectrum of the free ligand exhibited a strong band at 1636 $\mathrm{cm}^{-1}$ due to $w C=\mathrm{N}^{.3-2,23}$ In the coordinated of the Schiff base ligand, the $\mathrm{C}=\mathrm{N}$ stretching frequency is displaced to a lower frequency. $\sim 1620 \mathrm{~cm}^{-1}$. The decrease in the frequency indicate a decrease in the $\mathrm{C}=\mathrm{N}$ bond order due to the coordination of the azomethine nitrogen to the cobalt. ${ }^{31.34}$ The IR spectra of the complexes 1-4 exhibit a bond about $2027 \mathrm{~cm}^{-1}$, which is characteristic of a coordinated azido ligand. 35

Electronic spectra for the free Schiff base ligand in acetone recorded in the $300-800 \mathrm{~nm}$ range. The spectrum exhibits a band at $402 \mathrm{~nm}\left(\varepsilon=219 \mathrm{M}^{-1} \mathrm{~cm}^{-1}\right)$ due to $n \rightarrow \pi^{*}$ transition. ${ }^{36}$

Electronic absorption spectra of the cobalt complexes in acetone recorded in UV-Vis region. The $n \rightarrow \pi^{*}$ band appears to be absent in the spectra of the Co(III) complexes. The complexes exhibit a strong band in the UV region 


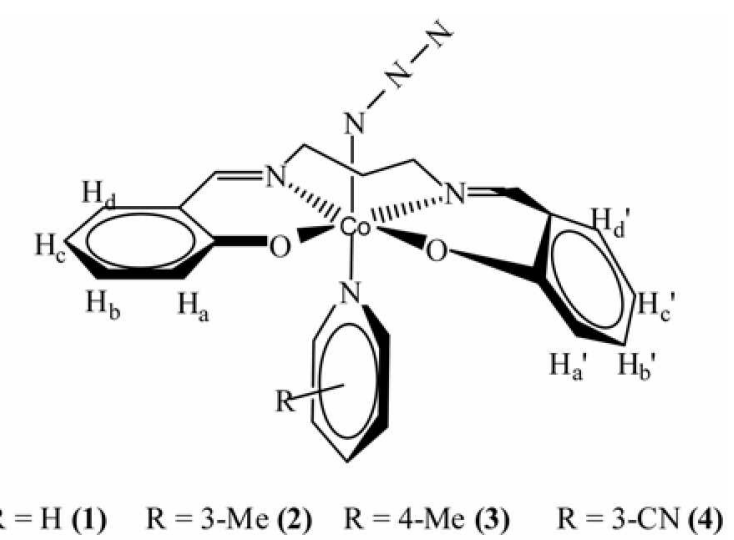

Figure 1. trans-[Co(salpri) $($ annine $\left.)\left(\mathrm{N}_{3}\right)\right]$ complexes $1-4$

corresponding to $d \rightarrow \pi$ charge transfer. The band at about $610 \mathrm{~nm}(1-4)$ and $565 \mathrm{~nm}(5$ and 6) is assigned to d-d transition.

The ${ }^{\mathrm{H}} \mathrm{H}$ NMR spectra data for the Scliff base region of complexes 1-6 are summarized in Table 1. The spectrun of the free ligand exhibits a signal at $\delta=13.52$, due to the intramolecular by hydrogen bonded the phenolic protons. ${ }^{37.38}$ The two equivalent inine protons $(-\mathrm{CH}=\mathrm{N})$ appear as a singlet at $8.58 \mathrm{ppm}$. The aromatic protons of the two equivalent phenyl rings in the free Schiff base appear as three well resolved signals centered at $6.90\left(\mathbf{H}_{a, c}\right) .7 .33\left(\mathbf{H}_{b}\right)$, and $7.43\left(\mathbf{H}_{\mathbf{d}}\right) \mathrm{ppm}^{38}$ (Fig. 1). The propanediamine protons shows a quintet at $2.02 \mathrm{ppn}$ due to two protons $\left(\mathrm{CH}_{2} \mathrm{CH}_{2}=\right.$ $\mathrm{CH}_{2}$ ) and a triplet signal at $3.68 \mathrm{ppm}$ due to four protons $\left(\mathrm{CH}_{2} \mathrm{CH}_{2} \mathrm{CH}_{2}\right.$ ).

The chemical shift pattern of the free ligand $\mathrm{H}_{\mathbf{s}} \mathrm{salpn}$ is relatively simple spectrum. the two half of the Schiff base being equivalent by symmetry. It is clear that the ligand $\mathrm{H}_{2}$ salpn has a plane of symunetry passing through the carbon
(A)

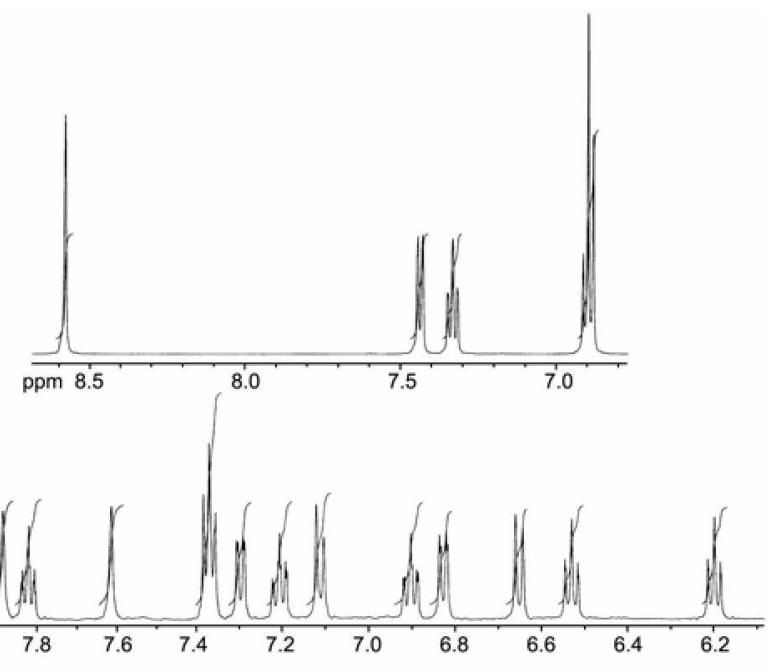

(C)

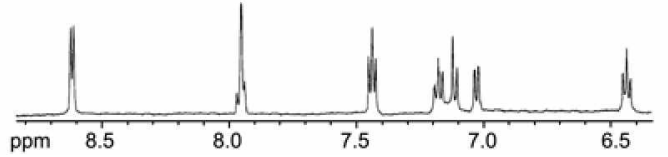

Figure 2. 'H NMR spectra for the Schiff base region of tree Schiff base (A), trans-[Co(salpn) $\left.(p y)\left(\mathrm{N}_{3}\right)\right]$ complex (B) and trans$\left[\mathrm{Co}(\mathrm{sel} \mid \mathrm{pn})(\mathrm{py})_{2}\right]$ complex $(\mathrm{C})$

atom in the middle of the propanediamine fragment.

The ${ }^{3} \mathrm{H}$ NMR spectra of complexes $1-4$ are very complex and showed more peaks than expected. The spectra showed that the two halves of the Schiff base moiety are not equivalent. For example. in complexes 1-4, the two inine protons appear as two individual singlets (Table 1. Fig. 2). Also the eight protons of the two phenyl rings in the complexes 1-4 exhibit eight peaks with equi-integration (Table 1, Fig. 2).

The number of signals from the Schiff base moiety in the complexes 1-4 in the ${ }^{1} \mathrm{H}$ NMR spectra rules out the presence

Table 1. 'H NMR spectra data for the Schift base region of complexes 1-6 ${ }^{a . b . c}$

\begin{tabular}{|c|c|c|c|c|}
\hline complex & $-\mathrm{CH}=\mathrm{N}$ & $-\mathrm{CH}_{2} \mathrm{CH}_{2} \mathrm{CH}_{--}$ & $-\mathrm{CH}_{2} \mathrm{CH}_{2} \mathrm{CH}_{2}-$ & Protons of phenyl rings \\
\hline 1 & $\begin{array}{l}7.62(1 \mathrm{H}, \mathrm{s}) \\
7.89(1 \mathrm{H}, \mathrm{s})\end{array}$ & $\begin{array}{l}2.16,2.45(2 \mathrm{H}, \\
\mathrm{m})\end{array}$ & $\begin{array}{l}3.63(1 \mathrm{H}, \mathrm{m}) \\
3.76(2 \mathrm{H}, \mathrm{m}) \\
5.03(1 \mathrm{H}, \mathrm{m})\end{array}$ & 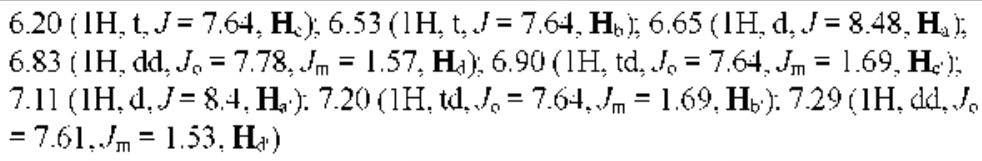 \\
\hline 2 & $\begin{array}{l}7.46(1 \mathrm{H}, \mathrm{s}) \\
787(1 \mathrm{H}, \mathrm{s})\end{array}$ & $\begin{array}{l}2.17,2.45(2 \mathrm{H}, \\
\mathrm{m})\end{array}$ & $\begin{array}{l}3.53(1 \mathrm{H}, \mathrm{m}) \\
370(2 \mathrm{H}, \mathrm{m}) \\
4.90(1 \mathrm{H}, \mathrm{m})\end{array}$ & 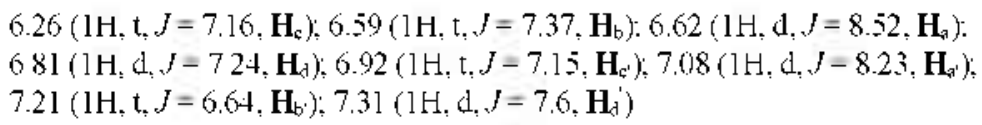 \\
\hline 3 & $\begin{array}{l}7.61(1 \mathrm{H}, \mathrm{s}) \\
7.88(1 \mathrm{H}, \mathrm{s})\end{array}$ & $\begin{array}{l}2.16,2.43(2 \mathrm{H}, \\
\mathrm{m})\end{array}$ & $\begin{array}{l}3.62(1 \mathrm{H}, \mathrm{m}) \\
3.76(2 \mathrm{H}, \mathrm{m}) \\
5.02(1 \mathrm{H}, \mathrm{m})\end{array}$ & 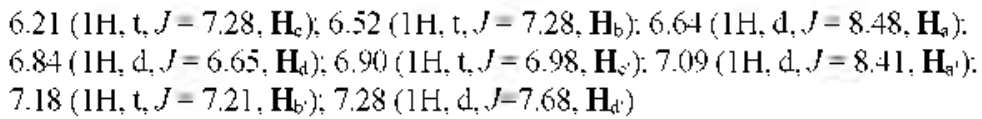 \\
\hline 4 & $\begin{array}{l}7.68(1 \mathrm{H}, \mathrm{s}) \\
7.87(1 \mathrm{H}, \mathrm{s})\end{array}$ & $\begin{array}{l}2.18,2.45(2 \mathrm{H}, \\
\text { mi) }\end{array}$ & $\begin{array}{l}3.67(\mathrm{lH}, \mathrm{m}) \\
3.76(2 \mathrm{H}, \mathrm{m}) \\
5.07(\mathrm{lH}, \mathrm{m})\end{array}$ & $\begin{array}{l}6.25\left(1 \mathrm{H}, \mathrm{t}, J=7.48, \mathbf{H}_{c}\right) ; 6.56\left(1 \mathrm{H}, \mathrm{t}, J=7.49, \mathbf{H}_{\mathrm{b}}\right): 6.70\left(1 \mathrm{H}, \mathrm{d}, J=8.45, \mathbf{H}_{\mathrm{a}}\right): \\
6.88\left(1 \mathrm{H}, \mathrm{d}, J=6.50, \mathbf{H}_{\mathrm{d}}\right) ; 6.96\left(1 \mathrm{H}, \mathrm{td}, J_{0}=7.15, J_{\mathrm{m}}=1.50, \mathbf{H c}\right) ; 7.14(1 \mathrm{H}, \mathrm{d}, J \\
\left.=8.47, \mathbf{H}_{\mathrm{a}}\right): 7.24\left(1 \mathrm{H}, \mathrm{t}, J_{0}=6.89, J_{\mathrm{m}}=1.60, \mathrm{H}_{\mathrm{b}}\right) ; .7 .31\left(1 \mathrm{H}, \mathrm{d}, J=7.60, \mathrm{H}_{\mathrm{d}^{\prime}}\right)\end{array}$ \\
\hline 5 & $7.95(2 \mathrm{H}, \mathrm{s})$ & $2.63(2 \mathrm{H}, \mathrm{m})$ & $\begin{array}{l}3.90(4 \mathrm{H}, \mathrm{t} \\
J=3.13)\end{array}$ & 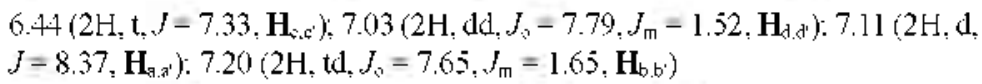 \\
\hline 6 & $7.93(2 \mathrm{H}, \mathrm{s})$ & $2.60(2 \mathrm{H}, \mathrm{m})$ & $\begin{array}{l}3.87(4 \mathrm{H}, \mathrm{t} \\
J=5.18)\end{array}$ & $\begin{array}{l}6.43\left(2 \mathrm{H}, \mathrm{t}, J=7.30, \mathbf{H}_{s,}\right): 7.04\left(2 \mathrm{H}, \mathrm{dd}, J_{0}=7.74, J_{\mathrm{m}}=1.54, \mathbf{H}_{\mathrm{d}, \mathrm{d}^{\prime}}\right): 7.1 \mathrm{l}(2 \mathrm{H}, \mathrm{d}, \\
\left.J=8.42, \mathbf{H}_{\mathrm{g}, \mathrm{s}^{\prime}}\right): 7.2 \mathrm{l}\left(2 \mathrm{H}, \mathrm{t}, J_{0}=7.6 \mathrm{l}, J_{\mathrm{m}}=1.62, \mathbf{H}_{\mathrm{b}, \mathrm{b}}\right)\end{array}$ \\
\hline
\end{tabular}

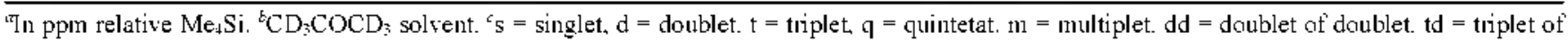
doublet 
of plane symmetry. Increasing the number of the methylene groups in diamine chain of the Schiff base causes distortion of the geometry of the salpn ligand in the complexes 1-t. The distortion of the Schiff base moiety from planarity could be due to the bonding geometry of the axial azido ligand. Bending of the Co- $\mathrm{N}_{3}$ bond (angle of $116^{\circ}$ and $120^{\circ}$ has been reported for similar complexes ${ }^{39,+11}$ ). causes steric interactions between the azido axial ligand and salpn ligand. The trans-[Co(salpn)(amine) $\left.)_{2}\right] \mathrm{ClO}_{4}$ contplexes were studied in order to further establish the importance of steric factors. The ${ }^{1} \mathrm{H}$ NMR spectra of solution of the complexes 5 and 6 were simple. Only four different signals were observed due to the Schiff base moiety. indicating the presence of symmetry plane. like that found in the free ligand. This indicates that the flexibility of salpn itself is not enough to cause distortion of the complexes, and another factor (steric interactions) must be present. However, steric interaction alone could not be responsible for distortion of the Schiff base moiety, as Complexes with acacen or salen and azido axial ligand have not shown distortion from planarity. ${ }^{11}$ Both the flexibility of the salpn Schiff base. due to the long alkyl chain. and the steric repulsion of the azido axial ligand, are necessary to cause part of the Schiff base to be forced away from the azido axial ligand toward the amine axial ligand. We suggest the existence of remarkable intramolecular $\pi-\pi$ interactions in the complexes 1-4. The distorted structure is further stabilized by $\pi$ - $\pi$ interactions between the amine aromatic ring and the $\pi$-system of the salpn Schiff base. The greater complexity of the ${ }^{1} \mathrm{H}$ NMR spectra is due to steric interaction between axial $\mathrm{N}_{3}$ and Schiff base ligand. which cause the difference in orientations of the two half Schiff base with respect to the axial anine. The up field shifts of this half of the Schiff base proton signals with respect to the other half are attributed to the shielding effect of the anine aromatic ring located near these protons. ${ }^{41}$

\section{Conclusion}

A series of octahedral cobalt(III) complexes with the salpn Schiff base ligand and relatively strong $\pi$-acceptor ligands have been sy'nthesized and their coordination chemistry has been investigated. Our results from the ${ }^{1} \mathrm{H}$ NMR studies on the complexes show that their geometric structure is affected by not only the structure of Schiff base ligand but also the steric effect of the axial ligand.

In all these complexes. the ${ }^{1} \mathrm{H}$ NMR spectrum showed that salpn Schiff base moiety had a distorted shape about the cobalt center. The differences observed in the ${ }^{1} \mathrm{H}$ NMR spectrum of salpn complexes 1-4 in comparison with the free ligand and with the symmetrical complexes 5 and 6 suggest that the complexes 1-4 lack symmetry plane in solution

Acknowledgments. This study was supported by the yazd university graduate school. We tank Dr. Elizabeth Krenske (Australian National University) for reading the manuscript and her valuable comments.

\section{References}

1. Berkessel. A.: Frauenkon. M.: Schwenkreis. T.: Steinnetz. T. Mol. Catal. A. Chem. 1997.117, 339.

2. Kovbasyuk, L. A.: Fritzy. I. O.; Kokozay, V. N.; Iskendevov, T. S Tetrahedron 1997, 16, 1723.

3. Nishinaga. A.: Tsutsui. T:: Moriyama. H. J. Mol Catal 1993. 83. 117.

4. Aminnasr. M.: Vafazadeh. R.: Mahmoudkhani. A. H. Com. J. Chem. 2002, 80, 1196.

5. Bottcher, A.; Takeuchi. T.: Hardeastle, K. I.: Meade, T. J.: Gray H. B.: Cwikel, D; Kapon, M. horg. Chem 1997. 36. 2498.

6. Fortunelli. A.: Colle. R.: Salvetti. O. Inorg. Chent 1991. 30. 2388

7. Hirota. S.: Kosugi. E.: Marzilli. L. G.: Yamauch. O. Inorg Chm Acta. 1998. 275.90

8. Urbach, F. L: Bereman, R. D.: Topich. J. A.: Hariharan. M: Kalbacher, B. J. J. Am. Chem. Soc. 1974. 96. 5063.

9. Ortiz, B.: Park. S. M. Bull. Korean Chem. Soc. 2000. 21. 405.

10. Amirnasr. M.: Schet1k. K. J.: Gorji. A.: Vafazadeh. R. Polwedhon 2001. 20.695.

11. Lindoy. L. F.: Louie. H. W. Inorg Chent 1981. 20.4186.

12. Botteher, A.; Elias, H.: Jager. E. G.; Langfeldmova, H.; Mazur, M: Muller. L.; Paulus, H.: Pelikan. P.: Rudolph. M.: Valko, M. Inorg. Chem 1993, 32,4131.

13. Zolezzi. S.: Spodine. E.: Decinti. A. Polyhedhon 2002. 21. 55.

14. Djebbar-Sid. S.: Benali-Baitich. O.: Deloume. I. P. Polhedhon 1997. 16.2175.

15. Djebbar-Sid. S.; Benali-Baitich. O: Deloume. J. P. J. Mol. Souct. 2001. 569, 121 .

16. Riley, P. E.: Pecoraro. V. L: Carrano, C. J.: Bonadies. J. A.: Raymond. K. N. horg Chom 1986. 25, 154

17. Calvin. M.: Barkelew. C. H. J. An. Chem. Soc. 1946. 68. 2267.

18. Weigold. H.: West. B. O. J. Chem. Soc. A 1967. 1310

19. Hariharan. M.: Urbach. F. L. Inorg. Chem. 1969.8.556.

20. Taylor, M. K; Reglinski. J; Wallace. D. Polyhedron $2004,23$. 3201 .

21. Nathan, L. C.: Koelnne, J. E:; Gilmore, J. M.; Hannibal. K. A.; Dewhirst. W. E.: Mai. T. D. Polhedron 2003. 22.887.

22. Hall. D.: Moore. F. H. Proc. Chen Soc. 1960. 256.

23. Hensont. N. J.: Hay. P. J.: Redondo. A. horg. Chent 1999. 38. 1618.

24. Green, M.: Tasker. P. A. Morg. Chin Acta. 1971, 5, 65 .

25. Averill. D. F. Broman. R. F. Inorg. Chem. 1978, 17, 3389.

26. Dreos. R.: Lucio. G. N.: Randaccio. L.: Siega. P.: Tauzher. G.: Vrdoljak. V. Inorg. Chin. Acta. 2003. 3+9. 239.

27. Hitchman1. M. A. Inorg. Chent 1977. 16. 1985.

28. Orgel, L. E. An Transition Metal Chemistry, Methuen \& Co. Ltd London 1966: 77.

29. Engelhardt, L. M.; Duncan. J. D.; Green, M. horg. Nucl. Chem. Letf. 1972. 8.725

30. Freddman. H. H. J. An Chen. Soc. 1970. 92.3197

31. Signorini. O.: Dockal. E. R.: Castellano. G.: Oliva. G. Polvhedron 1996. 15,245

32. Ueno, K.: Martel. A. E. J. Plys. Chem 1956, 60, 1270.

33. Yamazaki. N.: Hohokabe, Y. Bull. Chem. Soc. Jph. 1971. H4.63.

34. Zamian. T. R.: Dockal. E. R. Trons Met Chem. 1996. 21. 370

35. Nakamoto. K. Infrored Spectra of Inorganic and Coordination Contpoumds: Wiley: New York. 1972: p 192.

36. Bosnich, B. J. Am. Chem Soc. 1968,90.627.

37. Brown. N. M. D.: Nonhebel. D. C. Tetrahedron 1968. 24, 5655

38. Felicio, R. C.: Cavalheiro, E. T. G.; Dockal. E. R. Pohyledron 2001. 20.261

39. Clearfield. A.: Gopal. R.: Kline. R. J.: Sipshi. M.: Urbat1. L. O. J. Coord. Chent 1978.7.163

40. Massoud, S. S.: Mautner. F. A.: Abu-Youssef. M:- Shuaib, N. M Polvhedron 1999, 18. 2287

41. Kashiwabara, K, Ito, Y.: Kita. M.: Fujita, J.; Nakajima. K. d. Chen. Sac. Dalton Trons. 1997. 39. 